\title{
Elective Interdisciplinary Project Laboratories combined with Lectures on Demand as an innovative Teaching Method for Highly motivated Students
}

\author{
A. Bailleu, S. Kröger, M. Menge, A. Münchow-Carus \\ Hochschule für Technik und Wirtschaft Berlin - University of Applied Sciences \\ Department 1 - Energy and Information, \\ Wilhelminenhofstraße 75A, 12459 Berlin / Germany
}

\begin{abstract}
To join learning in interdisciplinary project teams and special lectures only offered on demand is a very effective and also an innovative teaching method for highly motivated students. This kind of teaching is characterized by very active participation by the students in the teaching process. Students exert influence on the contents in the projects and lectures during the course, professors exert influence of the scientific methods. The teaching process is consequently based on partnership of the students and the teaching staff.
\end{abstract}

Keywords: Interdisciplinary Project Laboratory; Soft skill exercising; Lectures on Demand

\section{Introduction}

At the Hochschule für Technik und Wirtschaft Berlin (University of Applied Sciences, HTW) we offer our students a new kind of elective courses for some semesters. In particular two consecutive courses are offered. Every course runs one semester. The first one is called Project Laboratory course, the second one is called Research and Development Laboratory course. Both courses arose within the context of natural science and of technology problems.

However, the subject matter of these courses isn't an expert knowledge of a special scientific discipline. Course participants should practice important soft skills instead. They get a methodological background and learn general fundamental methods to solve a problem.

Interdisciplinary team work and cross-cultural competences are the goal.

That's why these courses are open to all students (all terms and Bachelor's and Master's degree programs). That means students with different specialities (Engineering, Information Technology, Economics, Culture and Design) come to work and learn together in interdisciplinary and term-overlapping structures.

\section{Teaching Method}

\section{General description of the teaching method}

The teaching method is practice-orientated project work instead of lectures or classical tutorials. Classical lectures and tutorials are offered in these courses only as an additional support on demand. The teaching and administration staff consists of three full professors, one laboratory engineer and one student assistant. This team is supported by several other laboratory engineers and/or professors according to the relevant expertise which is needed. 
Normally an individual introduction for every participant and project proposal are given by the students and by the teachers during a first unit. This unit is one of only three units with compulsory attendance for all participants of the courses. So a lot of very different and interesting ideas for realizable projects are listed at the beginning of a course (Zahn, M., et al). A course runs only one semester.

Furthermore students get during this first unit a short lecture to basics of project management, team work, efficient communication structures, and presentation skills. Additionally the formalities concerning the conditions of examination and grading are clarified.

Then the students have to build small teams. A project team consists of two to six participants. Every project team has to choose a concrete project now. Often the teams realize a project idea of their own. That's why the students are highly motivated during the whole courses.

In each case one of the teaching staff is allocated as direct contact person for the project teams. Otherwise the teams work on their own without compulsory attendance in principle. The students are invited to use synergy effects of the other project teams.

Supervision and monitoring are organized in kind of intermediate colloquium for all participants of both courses after half-way through the semester. This and the examination unit at the end of the semester are those with compulsory attendance. Every participant has to present a part of the project team work there.

\section{Tasks of the teaching staff}

In addition to the monitoring of the projects, the teaching and administration staff ensures the smooth running of the courses: room and laboratory management combine with other tasks to ensure excellence are provided. The professors and laboratory engineers work as senior consultants for all projects in the both consecutive courses "Project Laboratory" and "Research and Development Laboratory".

As accompanying support the professors and laboratory engineers offer elective units on demand, for instance:

- Brainstorming sessions

- CAD-tools and CAD-systems (CAD: computer-aided design)

- EDA-tools (EDA: electronic design automation)

- Programming (LabVIEW)

- Data analysis

- Project planning and controlling (MS Project).

\section{Examinations}

Examinations of students consist of the individual oral presentations and discussions. In addition, there is a practical presentation of the project results by the project team. Furthermore the project teams have to deliver written project documentation, consisting of

- Description of the aims of the project

- Project plan (schedule, cost planning, role allocation in the project)

- Project results (experimental setups and measurement reports, mechanical drawings, wiring diagrams, layouts, printed circuit designs, source codes, etc.). 


\section{Results and Discussion}

\section{Special Facts and Project Results}

136 students took part in the course "Project Laboratory" so far. About 4\% of participants of this course drop out within four weeks for reasons of work overload, disinterest or difficulties with team building and integration. The other $96 \%$ have finished the course, most of them with very good results. About $60 \%$ of the projects were realized by interdisciplinary teams. $25 \%$ of the participants of the "Project Laboratory" course also attend the consecutive course "Research and Development Laboratory". This course was only offered in two semesters as yet.

Figures 1-9 show selected results realized by the students in the courses. Often the students look enthusiastically for solutions in context of biomedical applications or in context of energy generation during the project laboratories.

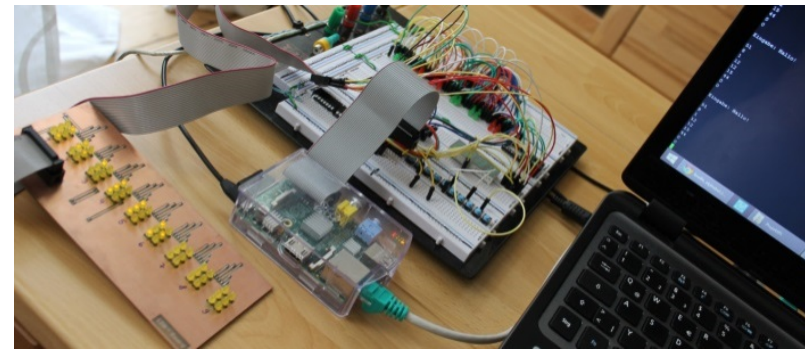

Figure 1. E-book-reader with Braille lettering output

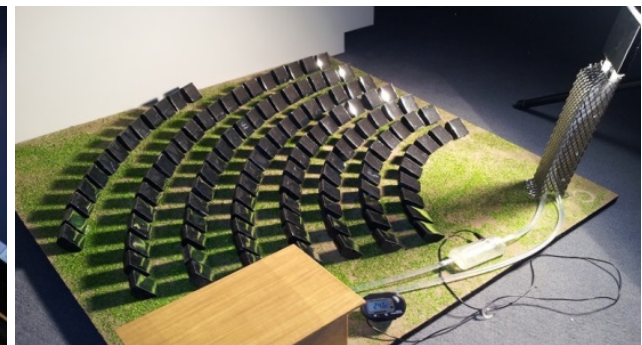

Figure 2. Model of a concentrated solar power plant (CSP)

As first example a part of the realisation of an e-book-reader with Braille lettering output is shown. It is possible to translate any text into Braille with this setup. You can see 9 segments, written is "hallo" (Figure 1). The Braille display is symbolized by LED cells. It provides 6 dots per cell. Every dot of the 9 cells is individually controlled by a microcontroller.

Another example shows a concentrated solar power model with a field of mirrors (Figure 2). The mirrors concentrate sunlight onto a central solar power tower. This model produces energy to warm up water.

Figure 3 shows an experimental setup of an apparatus uses falling water to generate voltage differences by electrostatic induction occurring between interconnected, oppositely charged systems. William Thomson (Lord Kelvin) invented this idea in 1867. The principle is described in (Zaiei-Moayyed M. et al). It becomes an interesting object to demonstrate the principles of electrostatics in physics and chemical education (Zaiei-Moayyed M. et al). The device resulting from this project was subsequent to the course used for teaching purposes in regular courses. This is one of the projects, which are continued in the second semester. In the "Research and Development Laboratory" course, the project team systematically investigated the influence of different parameters (as for example diameter of the vessels and concentration of salty solution) on the behaviour (e.g. the loading speed of the high voltage). 


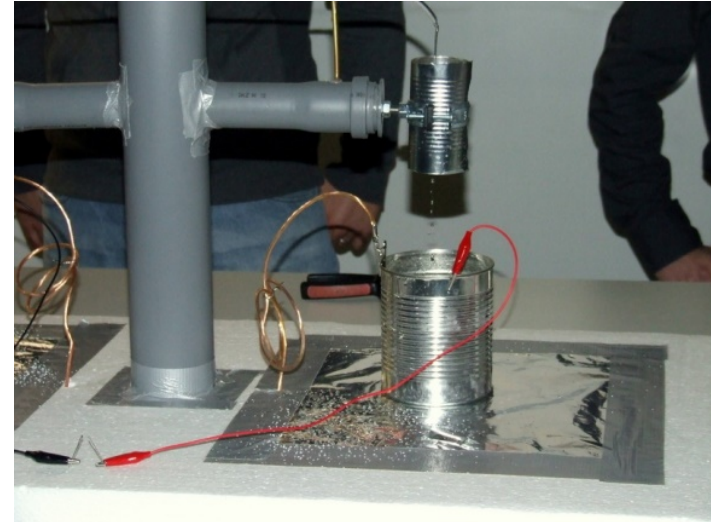

Figure 3. Kelvin water dropper as a kind of an electrostatic generator

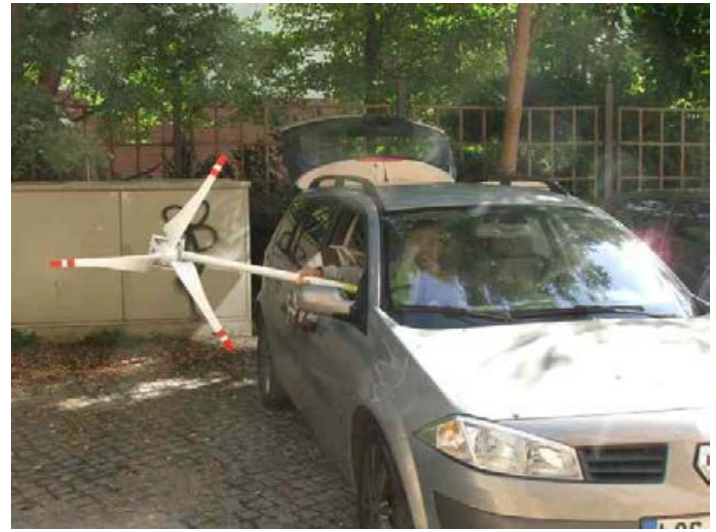

Figure 4. Self-made wind generator

The last but not least example of this group of projects is the self-made wind generator (Figure 4).

Such practical results (e.g. Figures 1-4) are impressive considering to the scheduled workload for the course (100 hours) and the very small budget (50 €) for the students. After finishing the projects the realized models are also sometimes used as demonstrators in regular lessons of other courses. Then it derives an additional benefit from the project laboratories.

Another idea of the Project Laboratory course was that the students should present their projects to the public, for example during an 'open day' at our university or on events in school. Besides the presentation exercises for the students, this is a good possibility to increase attractiveness and visibility of scientific and technical studies. Examples for projects, which have been presented to the public, are the investigation of the flow behaviour of non-Newtonian fluids (Figure 5) and the Theremin, an electronic musical instrument controlled by changes of electric capacity caused be the relative position of the hands (Figure 6).

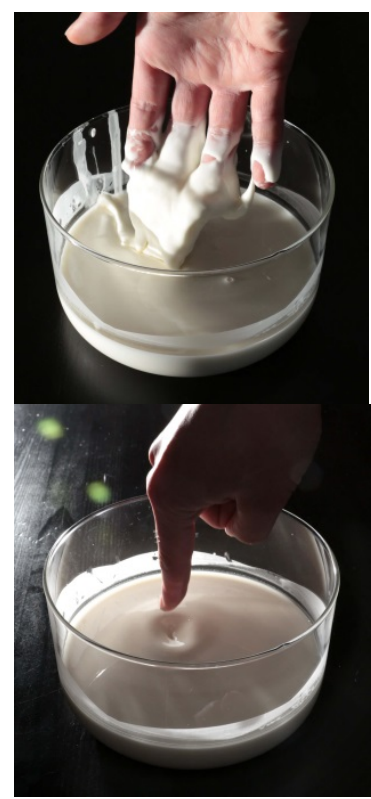

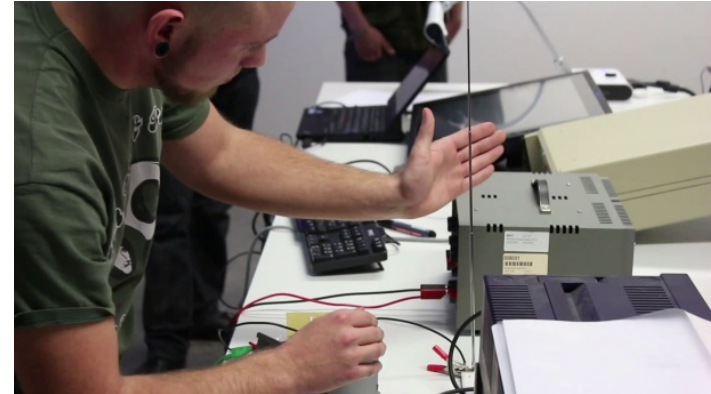

Figure 6. Theremin

Figure 5. Investigation of the flow behaviour of non-Newtonian fluids 
Other project results, e.g. the gimbals (Figure 7-9), appear almost like professional developments. These gimbals are the practical results of a project team of 2 highly motivated students. High-end materials and technologies to realize their ideas are used in these projects. Sponsoring is essential in such cases.

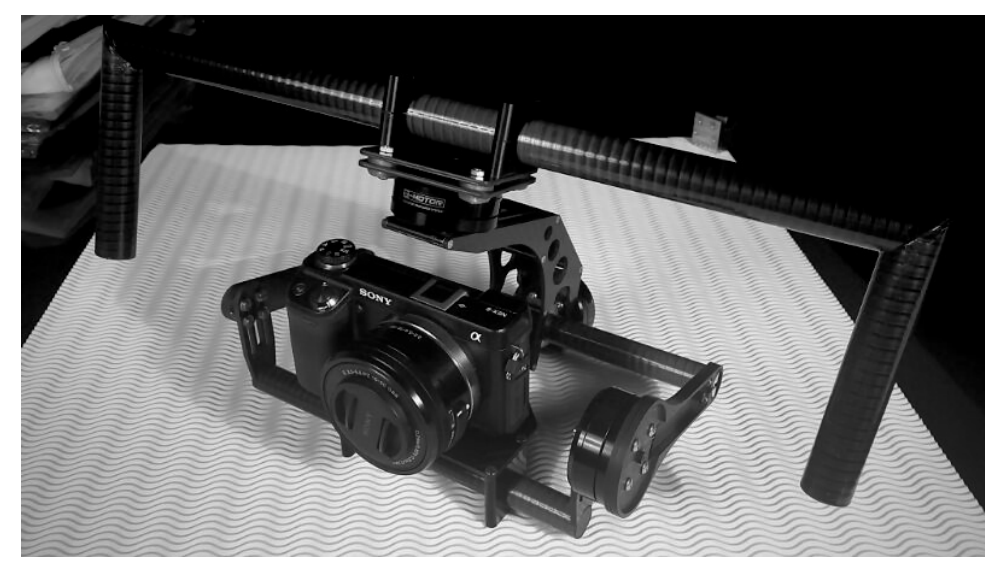

Figure 7. Gimbal 1for bigger cameras in helicopters

In Gimbal 1, developed and prototyped in the last semester for use in a helicopter (Figure 7), an industrial sponsor has been found. Gimbal 1 became an industrial duplicate part by now.

The Gimbal-project 2 (Figure 8, Figure 9) for GoPro-action-cameras and for industrial CMOS-cameras is a successor of the first Gimbal-project, because new applications were found in two current research projects of HTW Berlin.

Also in this case it derives a multiple benefit from the presented teaching method.

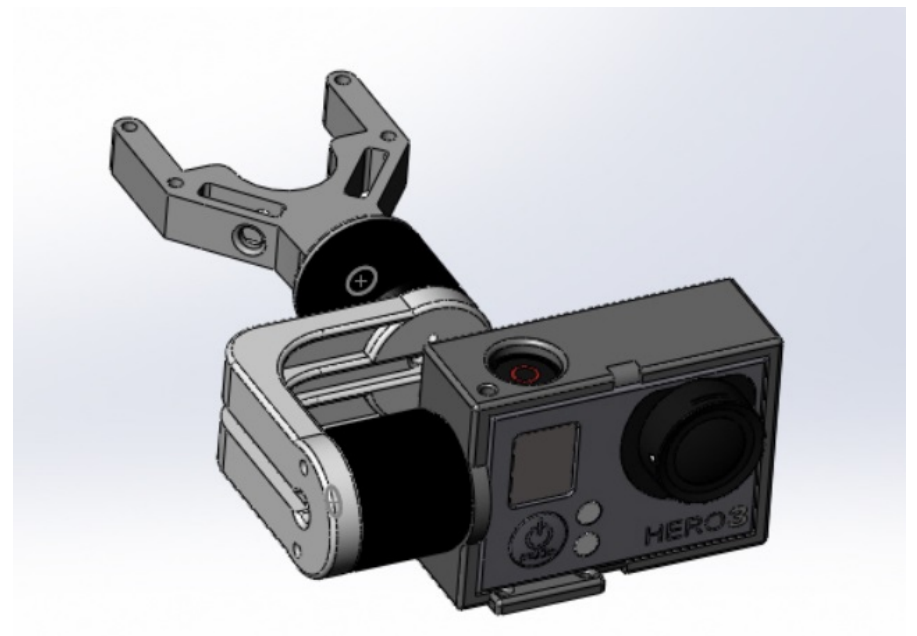

Figure 8. Construction of Gimbal 2 for use small cameras like GoPro-action- or industrial cameras

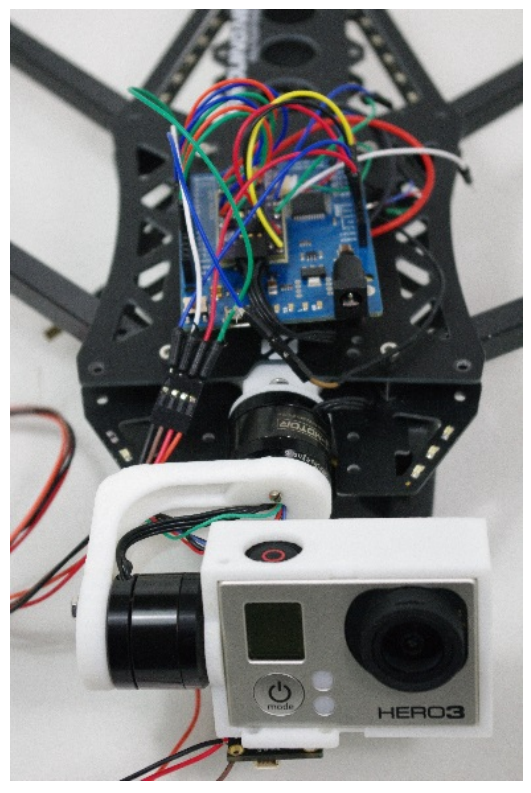

Figure 9. Realization of Gimbal 2 with GoPro-action-camera

The housing of the Gimbal 2 was produced with a 3D-printer. 


\section{Teaching field report}

Here are briefly illustrated the experiences of 5 semesters. 136 participants took part there.

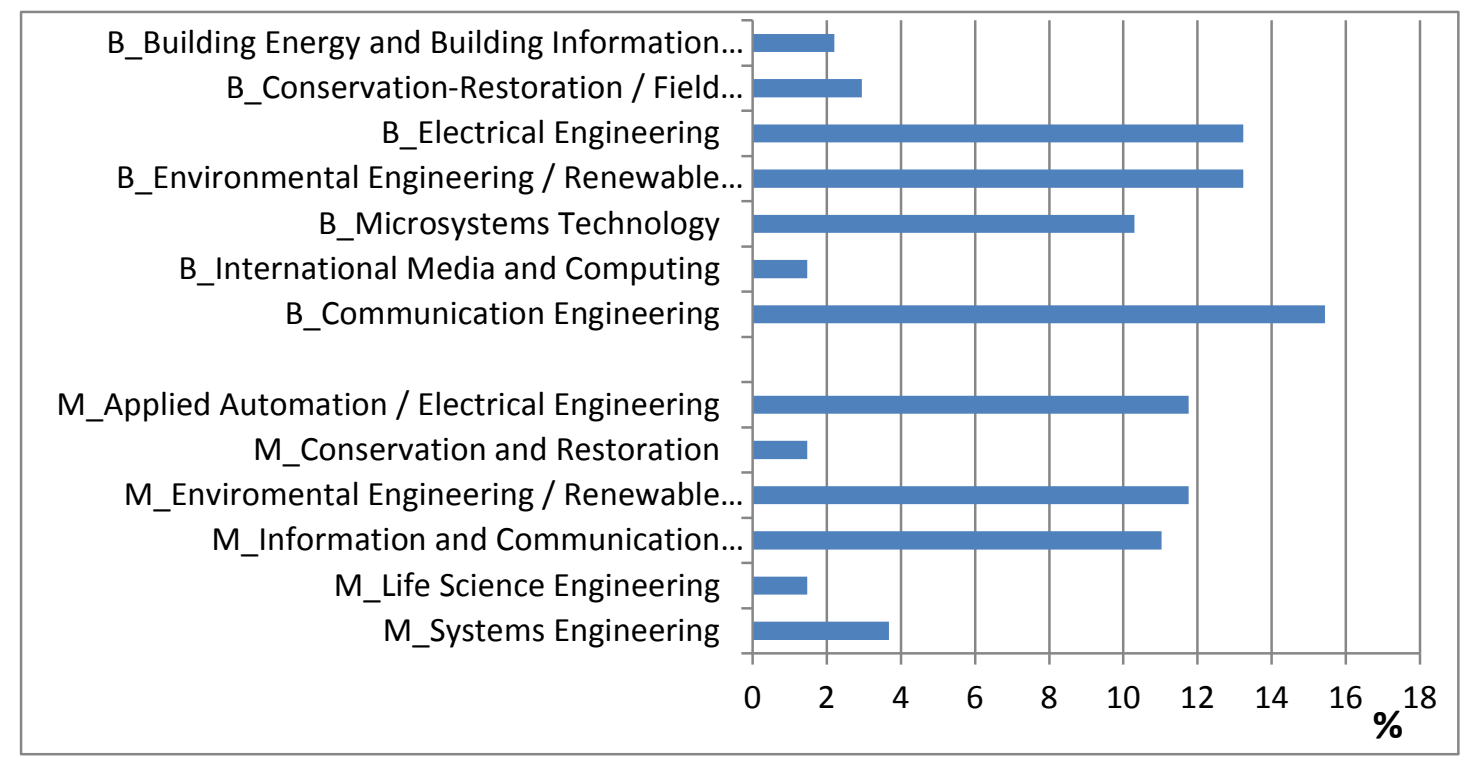

Figure 10. Bachelor’s (B_) and Master’s (M_) programs where the participants came from

$59 \%$ of all students came from the Bachelor's programs, $41 \%$ came from the Master's programs (Figure 10). Most of project teams consist of 4 members. Two member teams are often to find as well (Figure 11). 58\% of the project team were constituted interdisciplinary (Figure 12).

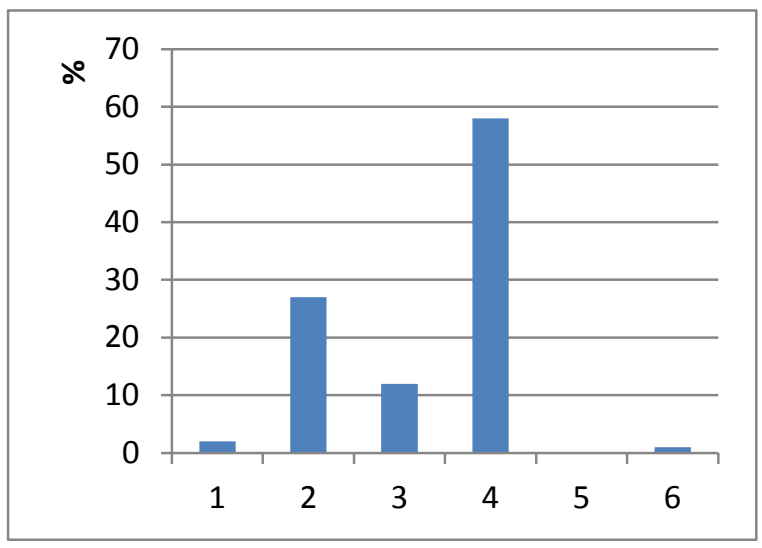

Figure 11. Number of team members

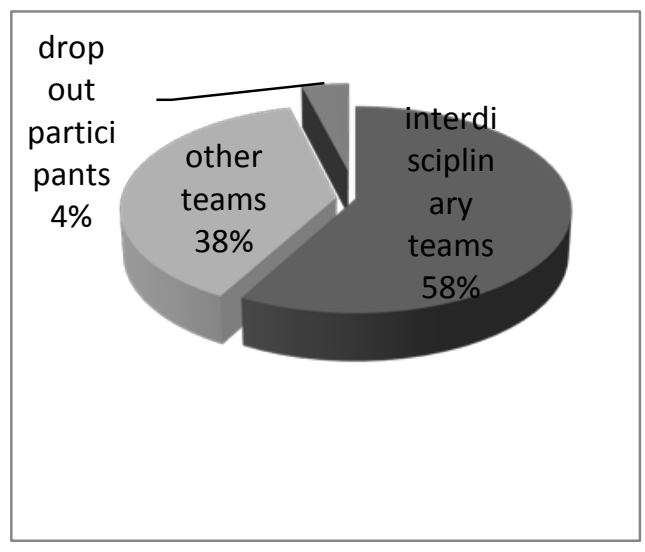

Figure 12. Constitution of the project teams

Although the consecutive course "Research and Development Laboratory" was only offered in two semesters, $25 \%$ of the participants of the first course also attend the consecutive second course. Success makes addicted!

To awareness that project laboratories joined with lectures on demand are a very successful teaching method for students and for the teaching staff, the number of participants of these elective courses is continuously high.

The most restricting fact to such kind of teaching is the financial basis. 


\section{Conclusions}

All in all, the presented teaching method has more advantages than disadvantages. A lot of students prefer to do some practical work during their studies. In the most cases they are very involved in their own projects. The learning process takes place nearly by the way because it is a kind of learning by doing. The students exert influence on the contents in the projects and lectures during the course, professors exert influence on the scientific methods. Point by point the students reach an advanced knowledge in a special scientific field but also in general fundamental approaches to solving a problem. The students acquire many important soft skills during working in an interdisciplinary project team. This is the most important significance of this teaching method.

Often especially such students which haven't the best success in normal, classical university courses excel by trying to get optimal project results. They are highly motivated from the beginning to the end of the project laboratories or they become highly motivated during the courses because of the direct feedback, the practical success, the appreciation of the team and of the teaching staff.

About $40 \%$ of the project results provide multiple benefits. Results can be taken as demonstrators in other courses. This means students learn by themselves and produce learning tools for other students in the same process. Sometimes the results can be used for a research project. Industrial products are developed in exceptional cases, too.

Our conclusion is: We recommend this teaching method. It is an interesting and a demanding kind of education, for the students and also for the teachers.

\section{Acknowledgements}

We gratefully acknowledge the head of university for benevolent support and the involved colleagues for active assistance.

The courses have been supported in the years 2012-2014 by the "Berliner Qualitätsoffensive für die Lehre" (BQOL)

Gimba1 1-project has been sponsored by Ingo Raeke.

\section{References}

http://home.htw-berlin.de/ kroeger/PL-Themenvorschlaege.html

Zahn, M. (1973), Self-excited a.c. high voltage generation using water droplets, American Journal of Physics, 41, 196-202.

Zaiei-Moayyed M., Goodman E., \& Williams P. (2000). Electrical deflection of polar liquid streams: A misunderstood demonstration, Journal of Chemical Education, 77(11), 1520-1524. 